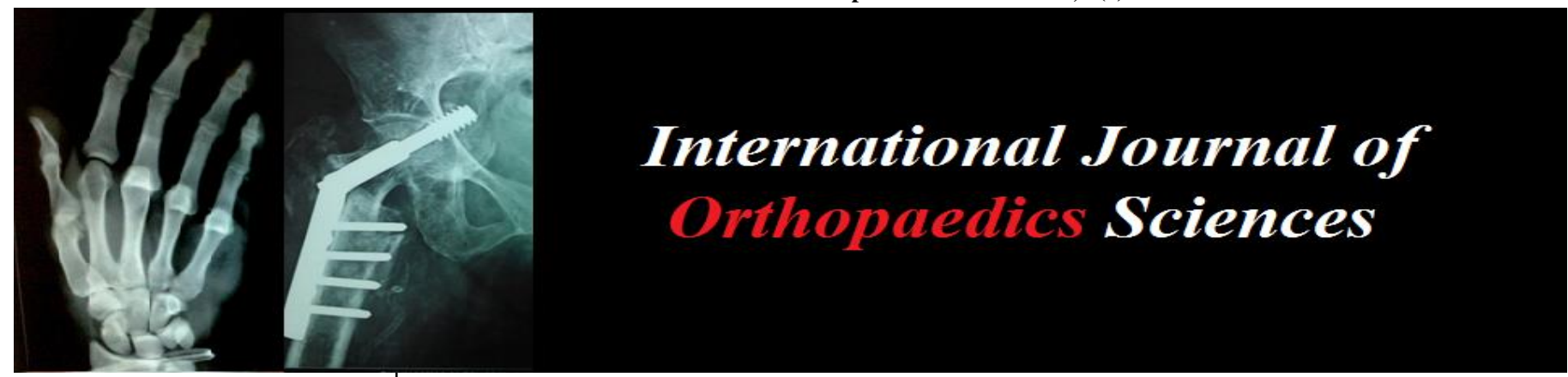

E-ISSN: 2395-1958

P-ISSN: 2706-6630

IJOS 2021; 7(4): 01-05

(C) 2021 IJOS

www.orthopaper.com

Received: 17-05-2021

Accepted: 04-07-2021

Dr. Rajesh K Ambulgekar Department of Orthopaedics, Dr SCGMC Nanded, College in Nanded, Maharashtra, India

Dr. Virendra Ramesh Khandekar Department of Orthopaedics, Dr SCGMC Nanded, College in Nanded, Maharashtra, India

Corresponding Author: Dr. Rajesh K Ambulgekar Department of Orthopaedics, Dr SCGMC Nanded, College in Nanded, Maharashtra, India

\section{Femoral exostosis causing vastus anterialis pain and restriction of knee range of motion in an active young male: A case report}

\section{Dr. Rajesh K Ambulgekar and Dr. Virendra Ramesh Khandekar}

DOI: https://doi.org/10.22271/ortho.2021.v7.i3m.2856

Abstract

A 38 year old male presented with a painful non mobile, bony hard swelling of lower end of Right femur of 6 month duration. The swelling was present since 6 months with progressive increase in size of the swelling, size of swelling was peanut shape when the patient noticed it $1^{\text {st }}$ time and it gradually increased to lemon size over the period of 6 months. Initially the swelling was painless nut since last 2 months patient started having pain which was aggravated by knee movements over anterior aspect of distal third of thigh. Clinical examination revealed a bony hard swelling arising from anterolateral aspect of lower end of femur away from the knee joint. The swelling was painful on knee movements.

MRI revealed rounded bony outgrowth on anterior aspect of distal femur of size $20 * 12 \mathrm{~mm}$ having mass effect on quadriceps tendon. A diagnosis of benign exostoses lower end femur was made. In view of sudden increase in size of the lesion and associated pain on knee movements, and mechanical obstruction Patient underwent surgical excision of the exostoses. Histopathology revealed osteochondroma \& no malignant transformation.

Keywords: Exostoses, osteochondroma, excision, Biopsy

\section{Introduction}

Osteochondroma is also known as an osteochondromatous exostosis ${ }^{[1]}$, osteocartilaginous exostosis ${ }^{[2,3]}$ or simply exostosis, is defined by World Health Organization (WHO), as bone projections enveloped by a cartilage cover that arise on the external surface of the bone ${ }^{[1]}$. Despite their predominant composition of bone, their growth takes place in the cartilaginous portion ${ }^{[2]}$. Debate continues as to whether osteochondroma is a developmental disorder (Pseudotumoral lesion) or a neoplasm ${ }^{[1]}$. They present two distinct clinical forms ${ }^{[3]}$ : single lesions (Solitary osteochondromas) and several lesions (multiple osteochondromas). Solitary form constitutes $10 \%$ of all bone tumors and, among these, $35 \%(20-50 \%)$ of the benign tumors $[1,4]$. Single lesions are found in $85 \%$ of the individuals diagnosed with osteochondroma ${ }^{[3]}$. The exostosis is commonly identified during childhood or adolescence ${ }^{[1,2]}$.

Osteochondromas more frequently affect the appendicular skeleton (upper and lower limbs).It most frequently occurs in the distal femur, proximal tibia and proximal humerus ${ }^{[3]}$. It rarely affects the proximal femur or the talus. Here I present one such case of femoral exostosis in a young active male

\section{Case Report}

\section{History}

A 38 year old male presented with pain and bony swelling overlying distal femur with decreased knee range of motion. Initially the swelling was small in size (peanut sized) and painless and bony hard in consistency. There was no associated pain or limitation in knee movements. However since last 2 moths there was pain and progressive increase in size of the swelling (lemon sized at present), and associated pain on knee movements. There was also difficulty in walking as the bony swelling was causing pain in distal thigh. There was no associated fever or skin breakdown. Patient had not taken any treatment since noticing the swelling. No history of similar bony swellings was there anywhere else in the body. 


\section{Clinical examination}

Clinical examination revealed a 38 year old male, with an illdefined bony mass arising from the anterolateral aspect of lower end of right femur. Skin over the mass was having a budget without any stretch.

On palpation the mass was painful on deep palpation. The surface of the mass was smooth and bony hard in consistency arising from bone and immobile. The lateral knee joint line could be palpated independently suggestive of a bony swelling arising from lower metaphyseal area of femur. There was mo raised local temperature and the edges of the mass were illdefined. The size of the mass clinically was approx $4 \mathrm{~cm} * 3 \mathrm{~cm}$. clinically there was no evidence suggestive of neurovascular compression.

Range of movements at right knee was painful and terminally restricted. When the patient flexed his knee there was pain in distal third of thigh. Clinical tests for ligaments and menisci around the knee were normal.
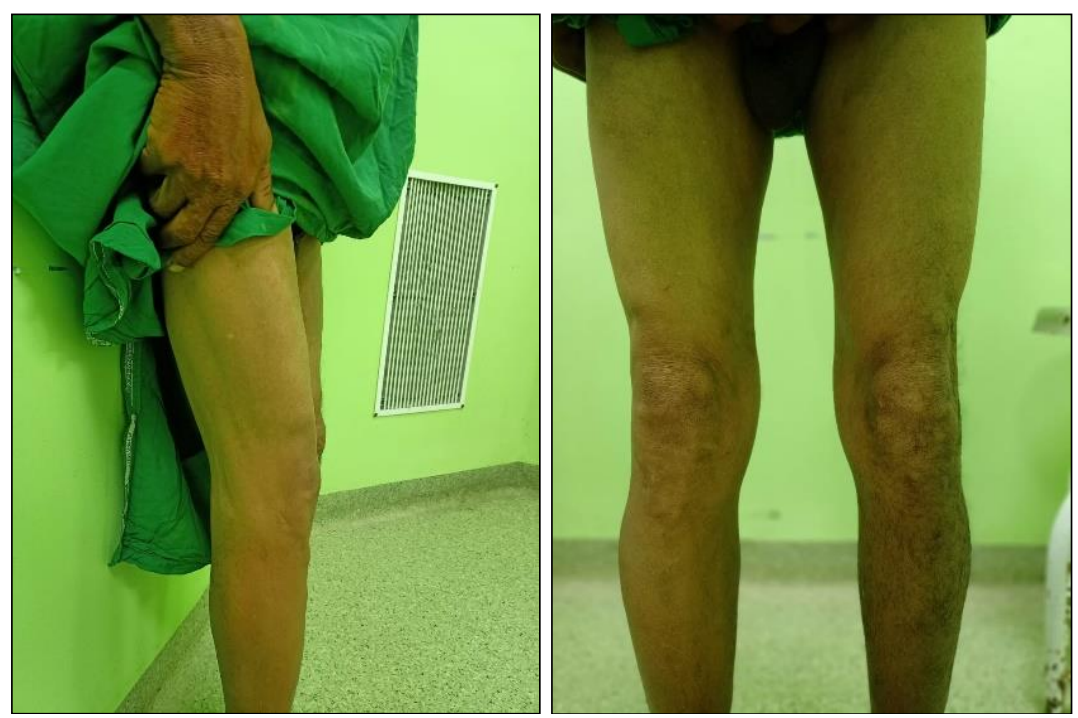

Fig 1, 2: Pre-op clinical images of patient

\section{Investigations}

Blood investigations -were within normal limits

$\mathrm{X}$ rays of Right femur with knee joint (Pic-1,2) revealed a pedunculated bony mass arising from anteromedial aspect of left lower end of femur, the medullary canal of mass was continuous with that of femur. Cartilage cap of the mass was fluffy. Diagnosis was suggestive of osteochondroma lower end of left femur.
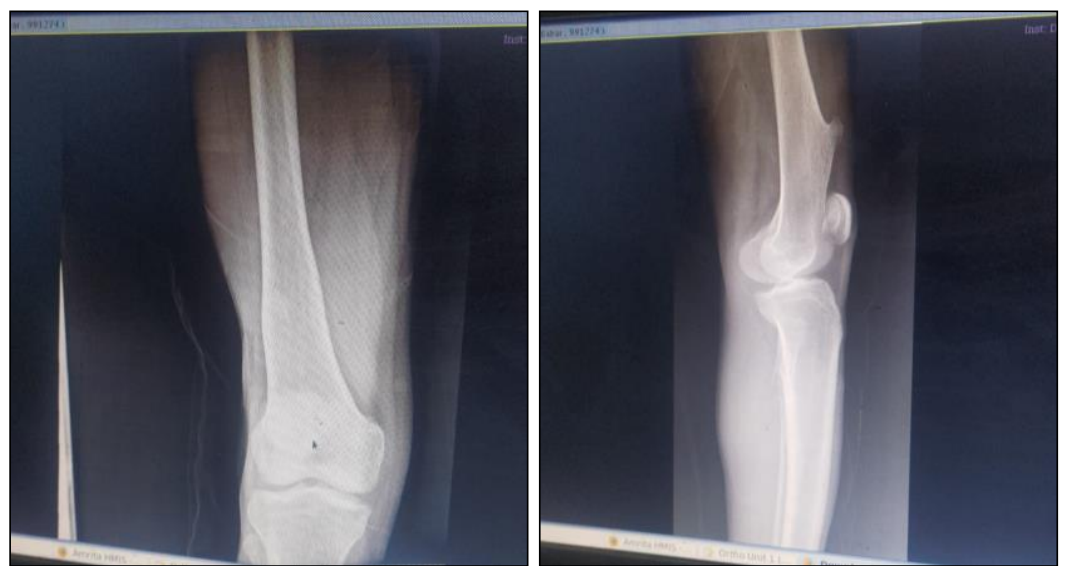

Fig 3, 4: Pre-op radiographic images of patient

MRI: Well defined rounded bony out growth seen along anterior aspect of distal femoral shaft region Size 20X12 mm It shows calcifications and chondroid matrix with mass effect on muscles and tendons mainly on quadriceps tendon with mild soft tissue edema No Mass effect on major vessels s/o bony benign exostosis osteochondrorna

Grade i-ii sprain of ACL

Minimal knee Joint effusion seen with grade Hi signal changes in posterior horn of medial meniscus 

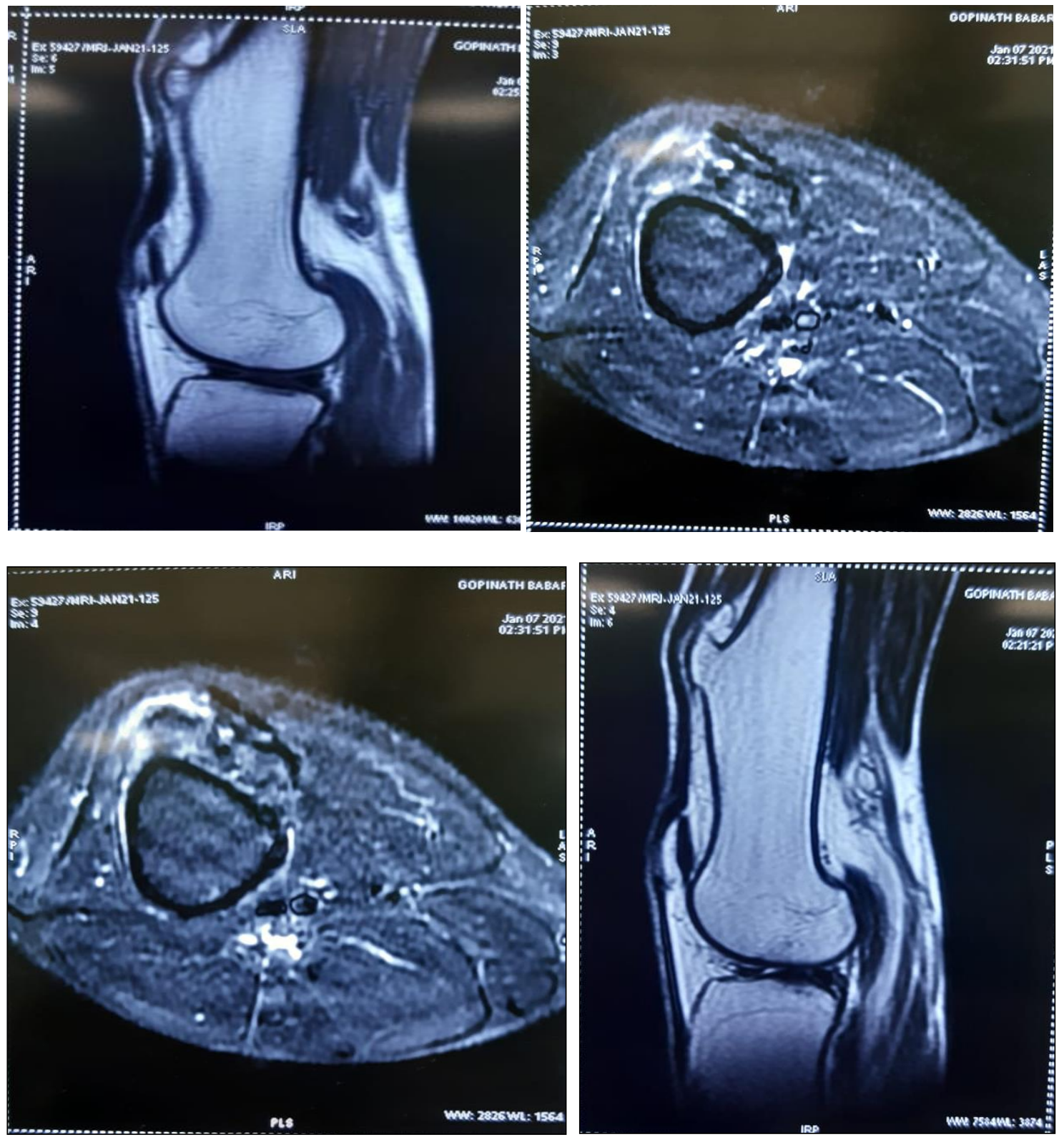

Fig 5-8: Pre-op MRI images of the patient

\section{Histopathology}

Gross: sample appeared bony tissue with hard consistency.

Microscopy: Histology section showed presence of cartilaginous tissue showing ossifications, bony trabeculae with presence of marrow tissue, adipose tissue and areas of haemorrhage.

\section{Impression: Osteochondroma}

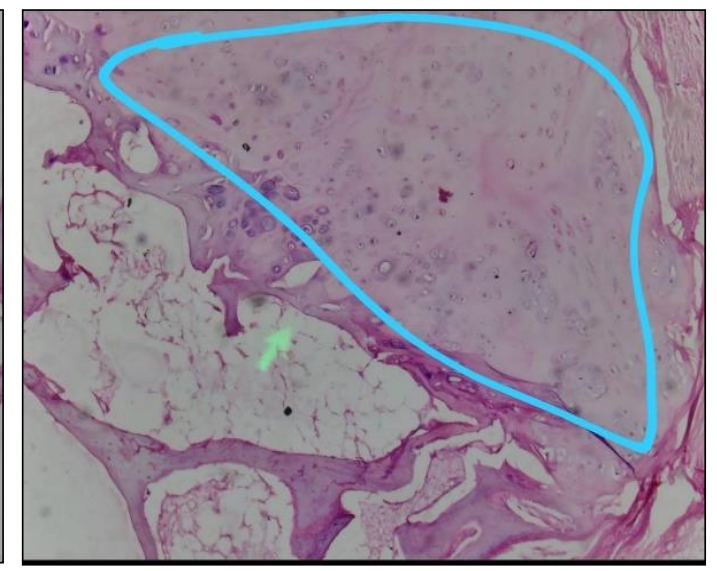

Fig 9, 10: Histology of the specimen excised 


\section{Treatment}

We decided to treat the patient with surgical excision \& histopathology to confirm the diagnosis and to rule out malignant transformation, to reduce pain and to relieve mechanical symptoms.

\section{Surgical procedure}

The lesion was approached through a lateral approach (lateral aspect of distal third of thigh $8 \mathrm{~cm}$ ), vastus lateralis muscle was bluntly dissected and the bony mass with cartilage cap exposed. The lesion was excised with a chisel and hammer of normal periosteum flush with parent bone. The tumor measure $4 * 3 * 3 \mathrm{~cm}$ (Pic). Sample was sent for histopathology.

The patient had an uneventful intra and post-operative period. Histopathology report confirm diagnosis of osteochondroma of distal femur.

Histopathology confirmed the diagnosis of osteochondroma with no features of malignancy. Patient had relief of pain and mechanical symptoms. At 3 months follow up patient had no pain or recurrence, and had full range of movements at the knee.

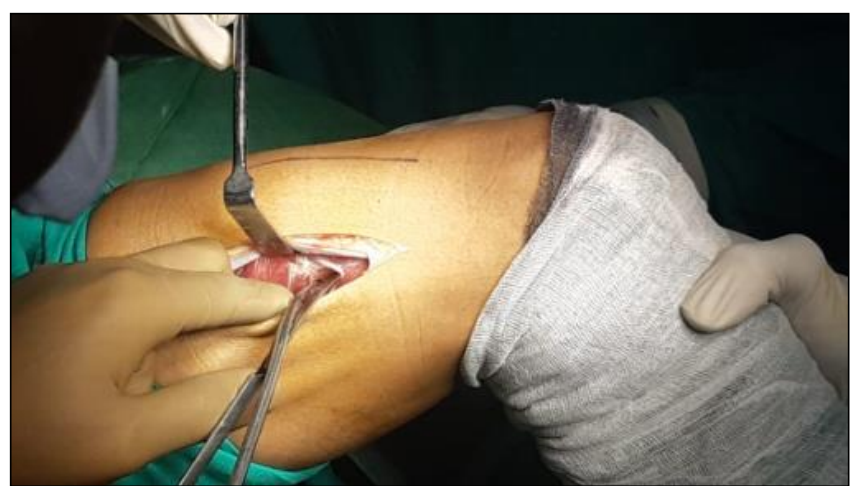

Fig 11: Intra-op picture of dissection

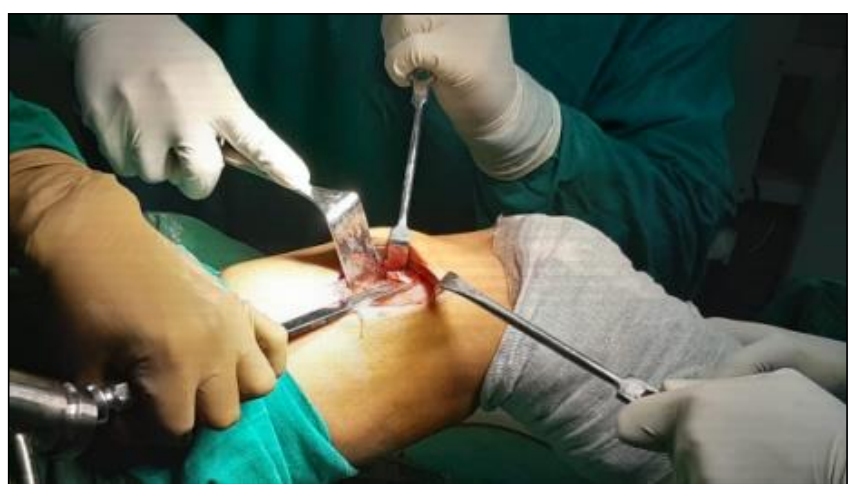

Fig 12: Intra op picture of excision of mass

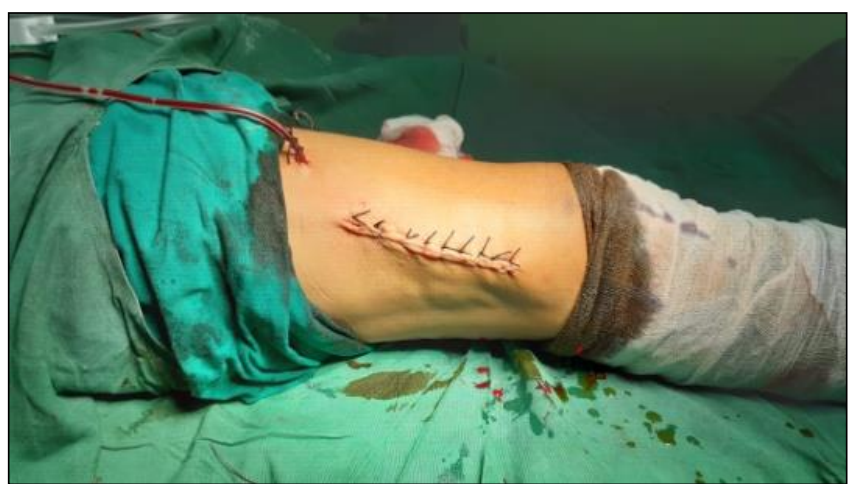

Fig 13: Intra op picture after closure of wound

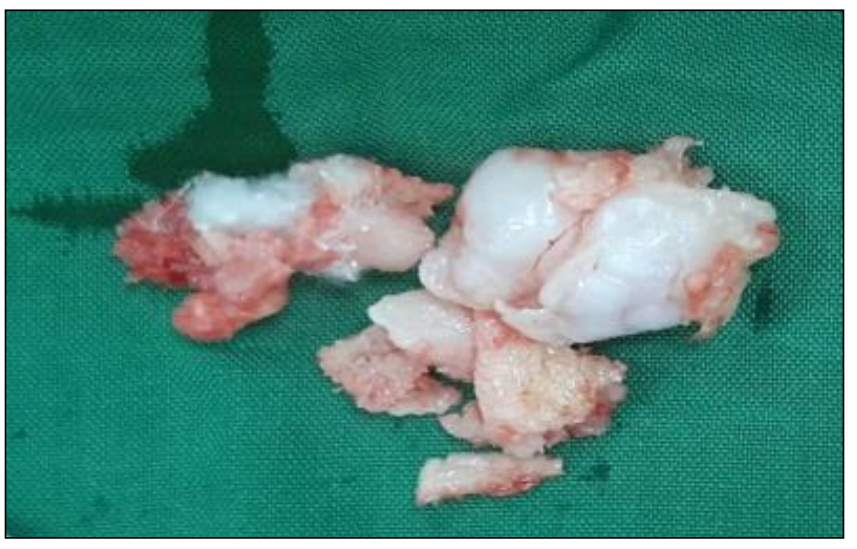

Fig 14: Excised tissue
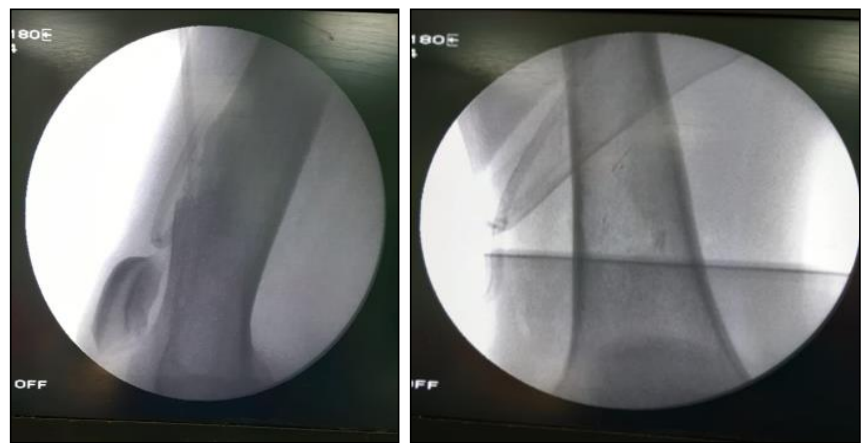

Fig 15, 16: Intra op CA rm shoot after excision

\section{Discussion}

Osteochondroma are most common benign bone tumors encountered. It is considered as a Developmental physeal abnormality rather than a primary bone neoplasm. Metaphyseal end of long bones like femur, tibia and humerus are its principal location $[5,6,7]$. In our case the age group and location was consistent with solitary osteochondroma patient was not able to recall any major or trivial trauma associated before appearance of the swelling. The gradual increase in size and associated pain on knee movements over the last month forced the patient to take medical opinion. Several studies have documented the likelihood of malignant transformation if there is sudden increase in size of solitary osteochondroma with associated pain ${ }^{[8,9]}$.

As the exostosis was having mass effect on vastus tendon and muscle patient faced difficulty/ pain during walking and running.

Although most solitary osteochondroma are asymptomatic, pain due to mechanical compression of surrounding neurovascular structures or fracture of the stalk are common symptoms to seek medical attention. The main reason for seeking medical opinion in our patient apart from pain was the cosmetic deformity. The X-ray appearance was typical of osteochondroma, however the cartilage cap was large and indistinct. Various studies have mentioned about the size of cartilage cap as a predictor for malignancy .In our case the presence of pain, limitation of knee movements, cosmetic deformity and the rare possibility of malignant transformation prompted us to perform surgical excision of the tumor. The tumor was excised completely with a cuff of normal periosteum. Patient had complete relief of his symptoms postoperatively. Histopathology confirmed the diagnosis of osteochondroma with no malignant transformation. At 3 month follow up patient was asymptomatic with complete knee movements. 


\section{Conclusion}

Osteochondroma usually present for cosmetic deformity as well as symptoms produced due to mechanical compression of surrounding structures. Sudden increase in size with associated pain should raise a suspicion of malignant transformation. Surgical excision gives consistent relief of pain and cosmetic deformity, and improves range of motion if restricted

\section{References}

1. Khurana J, Abdul-Karim F, Bovée JVM. Osteochondroma. In: Fletcher CD, Unni KK, Mertens F. Pathology and genetics of tumours of the soft tissues and bones. Lyon: IARC Press 2002, 234-7.

2. Unni KK. Osteochondroma. Dahlin's bone tumors: general aspects and data on 11,087 cases. 5th ed. Springfield: Thomas 1996, 11-23.

3. Dorfman HD, Czerniak B. Osteochondroma. Bone tumors. St. Louis: Mosby 1998, 331-46.

4. Resnick D, Kyriakos M, Greenway GD. Osteochondroma. In: Resnick D, editor. Diagnosis of bone and joint disorders. 3rd ed. Philadelphia: Saunders 1995, 3725-46.

5. Schajowicz F. Cartilage-forming tumors. In Tumors and Tumorlike Lesions of Bone. Pathology, Radiology, and Treatment. Ed. New York, Springer 1994;2:141-256.

6. Unni KK. Osteochondroma (osteocartilaginous exostosis). In Dahlin's Bone Tumors: General Aspects and Data on 11,087 Cases.Ed.5, pp. 11-23. Philadelphia, LippincottRaven 1996.

7. Canale \& beaty: Campbell"s operative orthopaedics 11th edition. Copyrigh MOS by an imprint of Elsevier 2007.

8. Bone and soft tissue pathology-Andrew 1. folpe, carrie y inwards-a volume in the series Foundations In Diagnostic Pathology, copyright by saunders an imprint of Elsevier, inc 2010, 331-335.

9. Canella P, Gardini F, Boriani S. Exostosis: development, evolution and relationship to malignant degeneration. Ital J Orthop Traumatol 1981;7:293-8. 